\title{
editorial
}

\section{Language barriers}

I usually write my editorials in about an hour - of course, I spend some time reflecting on the topic before I 'put pen to paper', but the writing itself comes easily once I have decided what to say. There are two reasons for this: English is my mother tongue, and the style and nature of an editorial gives me much freedom to put my thoughts into words. My 'ease of use' of English and the editorial style contrasts starkly with the difficulties faced by scientists for whom English is a second language, and who have to cope with the much more restricted style of a scientific report.

I think that we-those of us who grew up speaking English-greatly underestimate the extent of these difficulties for non-native speakers. I lived in France and Germany for many years, but I would have writer's block if I had to write something — let alone a scientific paper-in either language. Assuming I managed to write anything, the outcome would certainly be embarrassing from the grammatical perspective, stinted in style and would not convey any subtle gradations of the message. Yet, this is the reality that most scientists face, including those who work in Englishspeaking countries. But their difficulties are not restricted to writing; they also face a similar challenge-and perhaps embarrassment-when they have to present their results at an international meeting. In fact, if they turn out not to be fluent speakers, they are probably less likely to be invited to present again.

Yet, language-in the international sense-is not the only barrier; a scientific paper is a highly constrained and artificial format in the first place. My PhD supervisor was the editor of the Biochemical Journal at the time, and I gained early first-hand experience of a writing style that strips every personal idea and emotion from prose. For example, the claim "we have shown" is first altered to the more impersonal "it is shown" before being further diluted to the safer "it is indicated". Such expressions conceal the author's passion for his or her work and, in my view, strip the reporting of science of its human dimension.

Others have analysed the way in which 'scientific' language acts as a protective and excluding tool (Roland MC (2007) EMBO Rep 8: 424-428), or how the 'dry' and impersonal language of a scientific manuscript numbs the reader's senses, making it more difficult to follow and understand the arguments (Rodriguez-Esteban \& Rzhetsky, this issue, page 212). If scientists were to use a more personal and forthright style, it might not only be more readable, but it could also force scientists to take more responsibility for their results and interpretations-something that I think would be a good thingand not stand behind the illusionary barrier of archaic and formulaic expressions that obscure meaning.

One argument in favour of open access publishing has been that the public-who funds much of the scientific researchshould have free access to the scientific literature. Yet, as one commentator noted, the public would not bother to read scientific papers even if the journals were lying around for free, simply because scientific prose is largely unreadable for the non-expert-and often only barely readable for the expert.

Another consequence of the accepted scientific style and language is that authors have no leeway to build on their findings and propose new consequences of their research. Soon after EMBO reports was launched, we invited authors to engage in reasonable speculation, but this invitation has been largely ignored; scientists keep their ideas restricted to coffee-table discussions where 'wild' and sometimes brilliant ideas can be tossed around. Maybe one reason why scientists are coy about speculations is that they do not want to share their best thoughts with competitors. But referees also discourage speculative thinking with such withering lines as: "the extrapolations in the discussion are not supported by the data presented."
As Senior Editor of EMBO reports, I am often struck by the exciting and enthusiastic case made for a manuscript by its accompanying letter. Given the freedom to do so, scientists can, and actually do, expand on and explain their work, conveying their passion and highlighting the novelty of their results. By contrast, the actual paper usually avoids such insights and the reader has to be an expert to see why it is worthy of attention.

Again, non-English speaking authors are at an even greater disadvantage: their letters are often short and do not enthuse about or 'sell' their work. Obviously, editors and referees should not be swayed either way by an accompanying letter, but I suspect that not everyone is fully immune to a wellpresented argument. The same holds true for a response to an editor to address the criticisms of referees: being a fluent English speaker must be an advantage.

But this is the way it is. For the foreseeable future, English will remain the lingua franca of the scientific community for good reasons. However, there is nothing to stop scientists from undertaking a change of style that would make scientific papers more accessible and address the reader more directly. Or, as any good scientist would currently put it: "the possibility could be considered, taking into account various relevant factors, that a modest alteration in the mode of expression could, in due course and after a preliminary and statistically relevant trial period, be phased into the scientific discourse, such as an alteration focusing on the first person, but not exclusively, or a measured change from the passive to the active mode of writing."

\section{Frank Gannon \\ This Editorial represents the personal views of Frank Gannon and not those of Science Foundation Ireland or the European Molecular Biology Organization. \\ doi:10.1038/embor.2008.14}

